\title{
Mini OPCAB Mammary to Left Anterior Descending Artery
}

\author{
Federico Benetti*, Natalia Scialacomo \\ Cardiac Surgery, Benetti Foundation, Alem 1846, Rosario, Argentine \\ Email: *federicobenetti@hotmail.com
}

How to cite this paper: Benetti, F. and Scialacomo, N. (2017) Mini OPCAB Mammary to Left Anterior Descending Artery. Surgical Science, 8, 407-413. https://doi.org/10.4236/ss.2017.89044

Received: July 27, 2017

Accepted: September 3, 2017

Published: September 6, 2017

Copyright $\odot 2017$ by authors and Scientific Research Publishing Inc. This work is licensed under the Creative Commons Attribution International License (CC BY 4.0).

http://creativecommons.org/licenses/by/4.0/

\begin{abstract}
Introduction: Here we will describe the actual surgical technique to perform the left mammary artery bypass to the left anterior descending artery, and the results of this operation in the Benetti Foundation in the last 20 years. Materials and Methods: The inclusion criteria for this operation were patients with a demonstrated predominant ischemia by functional test. In the patients with double, triple vessels disease or left main, the age was more than 65 years or and Euro score Risk of surgery of more than 4 . The exclusion criteria were patients with more areas of ischemia and lesions that involved a considerable territory apart from the Lad and good candidates for surgery are younger than 65 years or the Euro score Risk of surgery were less than 4 . Seventy patients were operated in the Foundation through LIMA to LAD Anastomosis with the MINI OPCABG technique. The average Preoperative Risk Euroscore was 3,5. Surgical Technique after open the lower part of the sternum, the left mammary artery is dissected around $8 \mathrm{~cm}$. The pericardium is open and the mammary is connected to the left anterior descending. Results: Operative mortality in this series was $0 \%$. One patient was converted to sternotomy Off Pump (1,4\%). None of the grafts were revised after the measure with the Medistim System. 55 (79\%) were extubated in the operating room. The average Hospitalization stay were 60 hours (D +_17 ci 95\%), 16 patients with Lima to LAD were restudied in the initially experience with $100 \%$ patency, at 144 months, $82 \%$ of the patients were alive and $68 \%$ asymptomatic. Conclusion: More clinical experience is important to find the definitive indications of this technique; and better technologies are required to be able to standardize this operation in definitive form.
\end{abstract}

\section{Keywords}

Mini OPCAB, Minimally Invasive Coronary Surgery, Off Pump Coronary, 
Coronary Off Pump, Lima to Lad

\section{Introduction}

Trying to decrease the risks of the CABG and costs, in 1978 we popularized the Off Pump Coronary Artery Bypass Graft (OPCABG) and expanded the technique, addressing lesions of the circumflex system (CX) and applying it to diverse clinical scenarios [1] [2]. Several surgical approaches were tested, such as full sternotomy, no spreading sternotomy including left, anterolateral, posterolateral and right anterolateral thoracotomies, as well as partial sternotomy [3]. The video-assisted techniques in the nineties allowed, for the first time, to dissect the left internal thoracic artery (LITA) without opening the pleura cavity. The LITA was anastomosed to the left anterior descending (LAD) through a small left anterior thoracotomy [4] [5] [6]. In 1997, we performed for the first time an ambulatory coronary bypass through a xiphoid lower sternotomy incision (MINI OPCAB) using 3D technology to assist in the operation [7] [8].

Seventy patients were operated with the MINI OPCABG technique with LITA to LAD bypass during the last 20 years in our Foundation. The average age was 67 years, 15 (21\%) were female, $23(33 \%)$ patients had triple vessels disease, 18 (26\%) double vessels disease, 26 (37\%) single vessel disease, 3 (4\%) severe left main disease, 27 (39\%) had previous infarction, 12 (17\%) previous catheter intervention, 4 (6\%) previous CABG. The average Euroscore preoperative risk in this series was 3,5 (Table 1 ).

\section{Surgical Technique}

The patient is prepared as for standard Coronary bypass operation through sternotomy (Figure 1). The sternum is open up to the 3 or 4 intercostal space depending the anatomy (Figure 2). The mammary retractor is put place (Figure 3). The left mammary was dissected in general around $8 \mathrm{~cm}$ and isolated without

Table 1. Sociodemographic and clinicalcharacteristics.

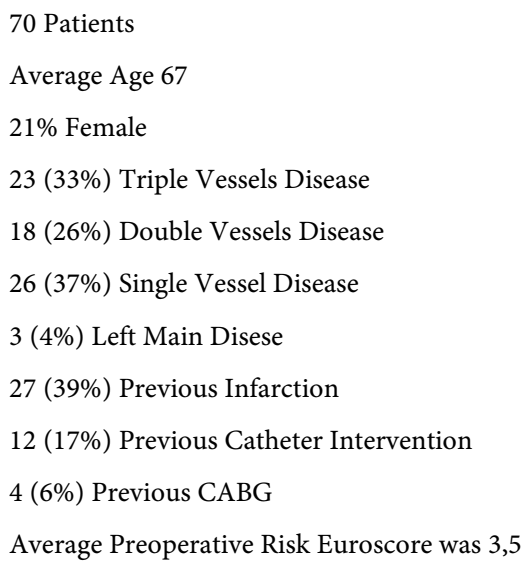




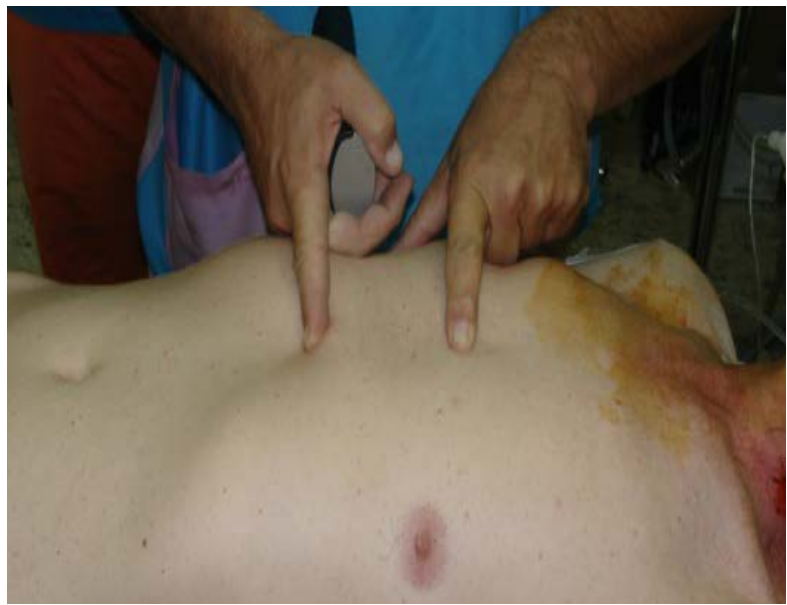

Figure 1. The patient is prepared for a normal sternotomybetween the fingers you can see the size of the incision.

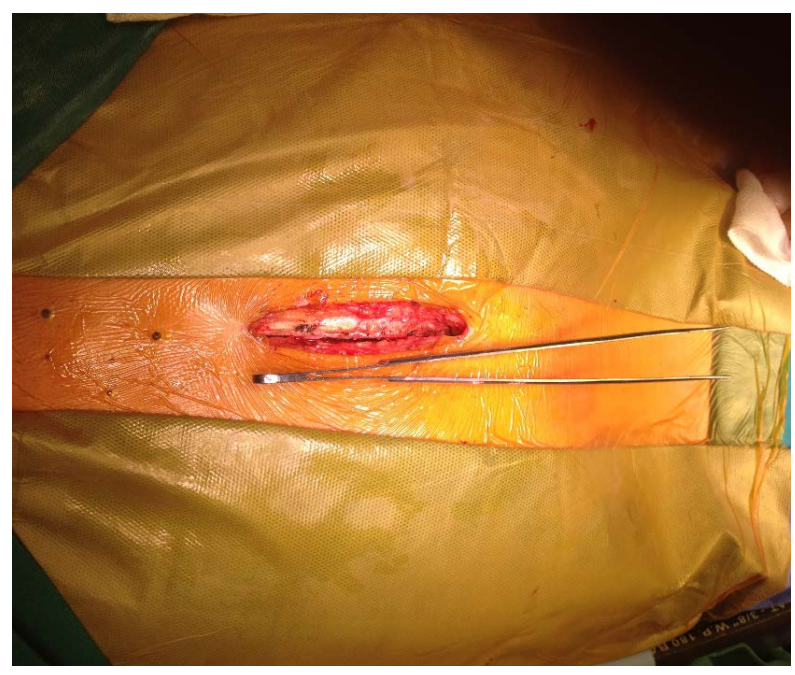

Figure 2. The sternum is open at the level of 3 or 4 intercostal space.

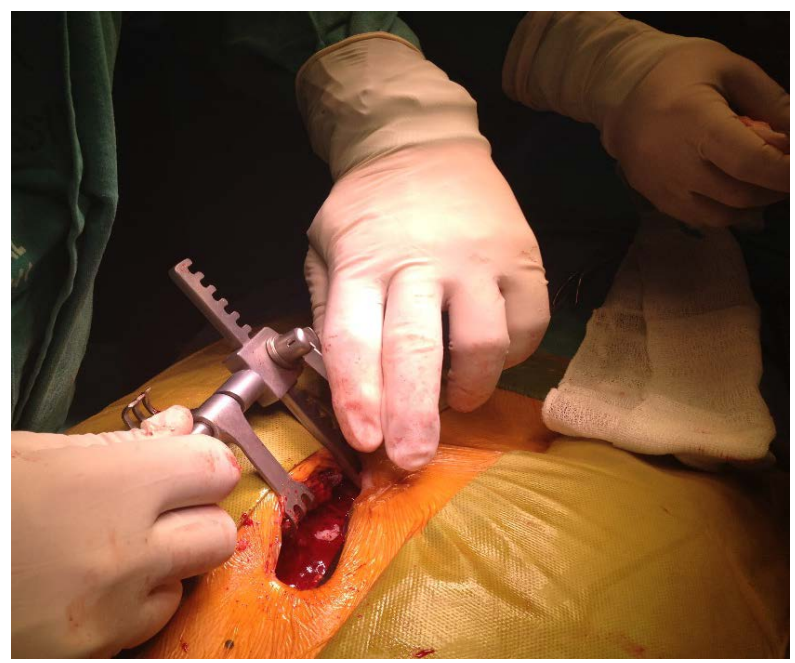

Figure 3. Mammary retractor in place. 
the veins (Figure 4). Importantly the angle of the superior part, were the mammary is attached to the sternum, needs to be below $20 \%$ to avoid any potential kinking. After the pericardium was cleaned to identify the area of the pulmonary artery. The pericardium is open to the apex and towards the right around 5 to 6 $\mathrm{cm}$ initially in that moment in most of the case the area of the LAD is seen and the potential area of the anastomosis is defined (Figure 5). The patient is heparinized and the LAD occluded with 5-0 Prolene.

The mechanical stabilizer is posisionate and the anastomosis is performed (Figure 6). When the bypass is finished, and before tied the suture the stitches of 5-0 polypropylene around the artery is released and the clamp of the mammary also and the anastomosis is tied. The mechanical stabilizer was take out, the stitches of the pericardium are released and the flow of the graft was measured being sure there is not any kinking, if the flow and the PR are ok the mammary is fixed with 2 stiches of 7-0 polypropylene in both sides around $1 \mathrm{~cm}$ from the

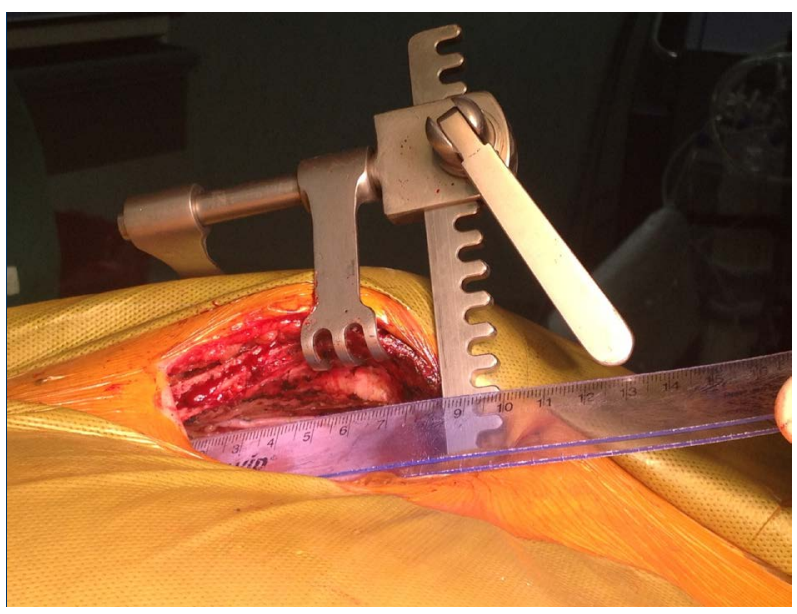

Figure 4. The mammary was dissected around $8 \mathrm{~cm}$ skeletonized and the anglein the upper part is below 20 degrees to avoid kinking.

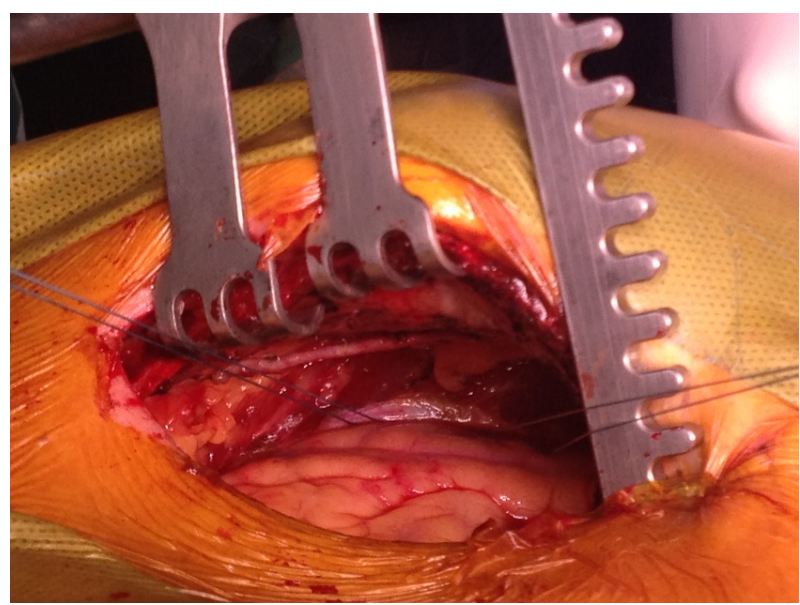

Figure 5. Visualization of the LAD and mammary showing the distances. 


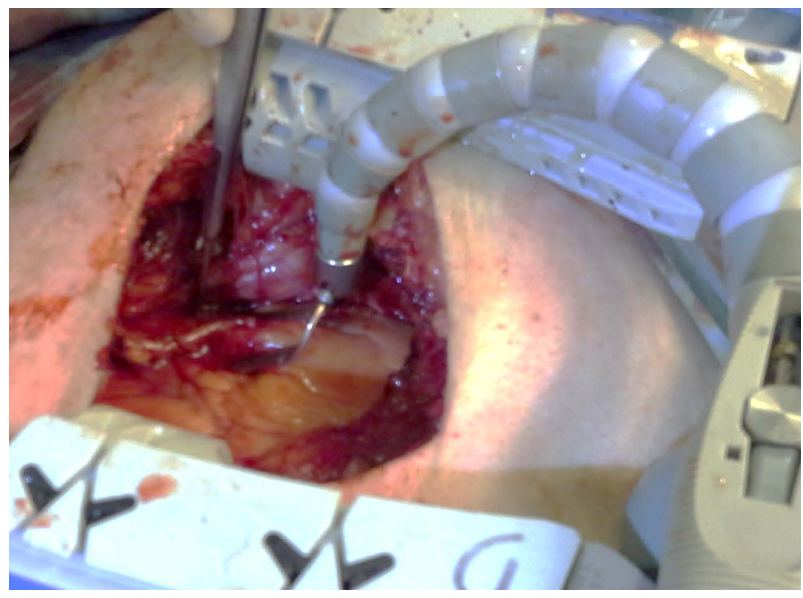

Figure 6. This picture shows the mammary to LAD anastomosis finished, the retractor and mechanical stabilizer in position.

anastomosis. The heparin is reverted with protamine, a drainage is put in placewith the caution of avoiding any chance of touching the mammary or the anastomosis. The sternum is closed with 1 or 2 wires.

\section{Results}

Operative mortality in this serie was $0 \%$; one patient was converted to sternotomy Off Pump $(1,4 \%)$ None of the grafts were revised after the measure with the Medistin System 55 (79\%) were extubated in the operating room The average Hospitalization stay were 60 hours (D +_17 ci 95\%), 16 patients with Lima to LAD were restudied in the initially experience with $100 \%$ patency; at 144 months $82 \%$ of the patients were alive and $68 \%$ asymptomatic [9].

\section{Discussion}

Old patients with multivessel coronary artery disease (CAD) are a challenging group to treat; these cases elicit discussion within heart teams regarding the actual benefit of undertaking major surgery on these patients and often lead to abandon the surgical option. Since these patients usually present with age-related comorbidities, preoperative risk stratification is mandatory and less invasive treatment options are favorable. Although conventional surgical revascularization can be carried out in old patients with acceptable short- and long-term results, perioperative mortality is markedly elevated [10]. For high-risk patients with multivessel CAD, not eligible to on-pump complete revascularization surgery or percutaneous procedures, incomplete revascularization with OPCAB LIMA-on-LAD offers benefits in survival when compared to OMT (Optimal medical treatment) alone [11].

Coronary surgery without extracorporeal circulation is routinely performed by different incisions; the operation of MIDCAB creates two obstacles to be able to externalize the patient in an immediate way; the pain and the opening of the 
left pleura that happen in the majority of the patients. The original technique without opening the pleura is difficult to reproduce in general [4] [5] [6]; the use ofIntravenous narcotics and the placement of a left pleural tube with possible complications of pneumothorax and pleural effusion are possible. The strategy of the operation of MINI OPCAB in general is simpler, and allows a possibility of more precocious externalization, in addition if it is necessary surgeon achieves complete access without modification of the incision only by extending the sternotomy; this factor is fundamental at the time of reproducing this operation. The dissectionof the left mammary artery can be performed safely using existing material, we prefer to use the skeletonized mammary always, in this specific technique is fundamental to avoid any kinking basically in the area the mammary attached at the sternum. The steal syndrome is related with the resistance of the anastomosis in our experience, so the intraoperative verification of the flow and resistance with the Medistim or other system is important to be sure of the quality of the anastomosis. This operation is undoubtedly ideal for the Hybrid of coronary treatment; that means; perform the coronary anastomosis first, and posteriori place the stents in the other arteries. The other advantage of this operation is that preserving the intact upper part of the sternum facilitates the alternative of a future operation on the aortic valve [12], besides preserving the best treatment and fundamental factor in the evolution of the majority of the patients with Coronary disease that is to have aLIMA to LAD anastomosis open; also decreasing the risk because in the operation the aorta is non touch [13] [14].

\section{Conclusion}

More clinical experience is important to find the definitive indications of this technique; and better technologies are required to be able to standardize this operation in definitive form.

\section{Disclose}

Both authors doesn't have any conflict of interested with this presentation.

\section{Statistics}

Data were analyzed with the Statistical Package for Social Sciences (SPSS, Version 15.0).

\section{References}

[1] Benetti, F. (1985) Coronary Surgery with Saphenous Vein Bypass without Either Bypass or Cardiac Arrest. The Journal of Cardiovascular Surgery, 26, 217-222.

[2] Buffolo, E., et al. (1985) Direct Myocardial Revascularization without Cardiopulmonary Bypass. The Thoracic and Cardiovascular Surgeon, 33, 26-29. ttps://doi.org/10.1055/s-2007-1014076

[3] Benetti, F.J., et al. (1991) Direct Myocardial Revascularization without Extracorporeal Circulation Experience in 700 Patients. Chest, 100, 312-316.

https://doi.org/10.1378/chest.100.2.312 
[4] Benetti, F.J., et al. (1994) Uso de la Toracoscopia en cirugía coronaria para la disección de la mamaria izquierda. La Prensa Medica Argentina, 9, 81-87.

[5] Benetti, F.J., et al. (1995) Use of the Thoracoscopy and a Minimal Thoracotomy in Mammary Coronary Bypass to Left Descending Artery, without Extracorporeal Circulation Experience in 2 Cases. The Journal of Cardiovascular Surgery, 36, 159-161.

[6] Benetti, F. Method for Coronary Bypass. United State Patent No 5888247.

[7] Benetti, F.J. (1999) Minimally Invasive Coronary Surgery (the Xiphoid Approach). European Journal of Cardio-Thoracic Surgery, 16, S10-S11.

[8] Benetti, F.J. (2004) Xyphoid Access for Cardiac Surgical Procedures. US Patent 6199556B1.

[9] Benetti, F.J. (2010) MINI-Off-Pump Coronary Artery Bypass Graft: Long-Term Results. Future Cardiology, 6, 791-795. https://doi.org/10.2217/fca.10.96

[10] Hoffmann, G., et al. (2016) Short- and Long-Term Follow-Up after Minimally Invasive Direct Coronary Artery Bypass. Interactive Cardiovascular and Thoracic Surgery, 23, 377-382. https://doi.org/10.1093/icvts/ivw149

[11] Prestipino, F., et al. (2016) Off-Pump Coronary Artery Bypass Grafting versus Optimal Medical Therapy Alone: Effectiveness of Incomplete Revascularization in High Risk Patients. Journal of Geriatric Cardiology, 13, 23-30.

[12] Benetti, F. (2008) eComment: No Need to Open the Upper Part of the Sternum to Measure the Length of the Left Internal Mammary Artery. Interactive Cardiovascular and Thoracic Surgery, 7, 1160-1161. https://doi.org/10.1510/icvts.2008.189100A

[13] Kowalewski, M., Suwalski, P., Pawliszak, W., Benetti, F., Raffa, G.M., Malvindi, P.G., et al. (2016) Risk of Stroke with "No-Touch"-As Compared to Conventional Off-Pump Coronary Artery Bypass Grafting. An Updated Meta-Analysis of Observational Studies. International Journal of Cardiology, 222, 769-771. https://doi.org/10.1016/j.ijcard.2016.08.041

[14] Zhao, D.F., Edelman, J.J., Seco, M., Bannon, P.G., Wilson, M.K., Byrom, M.J., et al. (2017) Coronary Artery Bypass Grafting with and without Manipulation of the Ascending Aorta: A Network Meta-Analysis. Journal of the American College of Cardiology, 69, 924-936. https://doi.org/10.1016/j.jacc.2016.11.071

\section{Submit or recommend next manuscript to SCIRP and we will provide best service for you:}

Accepting pre-submission inquiries through Email, Facebook, LinkedIn, Twitter, etc. A wide selection of journals (inclusive of 9 subjects, more than 200 journals) Providing 24-hour high-quality service User-friendly online submission system Fair and swift peer-review system Efficient typesetting and proofreading procedure Display of the result of downloads and visits, as well as the number of cited articles Maximum dissemination of your research work

Submit your manuscript at: http://papersubmission.scirp.org/

Or contact ss@scirp.org 